Commentary on Integrating Time-Limited Dynamic Psychotherapy

and a Buddhism-Inspired Aversion/Attachment Model

of Client Suffering: The Cases of "Beth" and "Amy"

\title{
On How Psychotherapy Can Be Helpfully Integrated Into Mindfulness Practice
}

\author{
DONALD MORGAN ${ }^{\mathrm{a}, \mathrm{b}}$ \\ a Graduate School of Applied and Professional Psychology, Rutgers University-New Brunswick \\ ${ }^{\mathrm{b}}$ Correspondence regarding this article should be sent to Donald Morgan, 2834 McNair Avenue, \\ Saint Louis, Missouri, 63118 \\ Email: dmorgan@rutgers.edu
}

\begin{abstract}
This commentary presents a discussion of some of the theoretical and technical aspects of Buddhist thought that Samlin used in his therapy with clients. The Buddhist roots of his "Attachment/Aversion Model of Client Suffering” are explored, and their origins in the Buddhist psychology known as Abhidharma are noted. The Abhidharma is placed within the context of modern theories of conditioning. I then outline how ideas and practices from the Buddhist tradition fit very well into the major contemporary psychotherapies, as Samlin shows using the TLDP model. Some reasons are presented for the advantages of integrating Buddhist thought and practices into psychotherapy. Finally, some practical suggestions are proposed for how to use this approach in psychotherapy with clients.
\end{abstract}

Key words: Buddhism and psychotherapy; dharma teachings in psychotherapy; psychological suffering; psychotherapy integration; Time Limited Dynamic Psychotherapy (TLDP); abhidharma in psychotherapy; mindfulness meditation in psychotherapy; present-centered attention in psychotherapy; case studies; clinical case studies

\section{INTRODUCTION}

OK, so the title may be a bit tongue-in-cheek, but we have all seen how "Mindfulness" has Trojan-horsed its way into just about everything and will likely continue to support most of the self-help industry for some time to come. But its utility and appeal when used as part of psychotherapy has support from 20 years of increasingly good empirical and clinical evidence, as can be seen from the bibliography in Samlin's (2016) fine contribution on the therapeutic usefulness of Buddhist and Yogic psychology and practices.

Samlin points out that there is a need for more discussion of the mindfulness aspects than he could include in the case reports, so I will first pick up on that thread and then discuss how ideas and practices from this tradition fit very well into the major contemporary psychotherapies, as Samlin shows using the TLDP model. Finally, I will review some reasons why one would 
integrate Buddhist thought and practices into psychotherapy, and offer some practical suggestions from my own clinical experience on what is helpful to use with clients.

\section{MINDFULNESS AND PSYCHOTHERAPY}

As Samlin has documented in his review, it is apparent that if you examine the psychotherapy literature over the past 20 years or so, Buddhist thought and practices have become a strong current flowing in the mainstream, and they flow mostly in the form of what has become known as mindfulness. Mindfulness is a translation of the term vipassana, from the ancient Pali language spoken by the Buddha. The more traditional translation has been "insight," which describes the "piercing" of ordinary consciousness of all phenomena and the understanding of its impermanent, insubstantial and ultimately unsatisfactory nature. As I have alluded to above, "mindfulness" has been appropriated in many ways now, and has come to signify any approach to psychotherapy, business, sport, and so forth that makes use of something like the following idea: Most of what the mind thinks is not worth paying attention to because it is the product of ignorance and the conditioning brought about by the transitory winds of wants and aversions that blow us in maladaptive ways. These teachings assert that by cultivating the ability to watch the mind and accept, but not respond reflexively to its momentary states, we will become more skillful in many ways in life and suffer less.

In other words, through the cultivation of mindfulness we can become more aware of how our thinking, our behavior, and our view of self is conditioned. Any of these can be worked with to remove our ignorance and limitations. Through the use of the prescribed Buddhist precepts, values and practices_-known as the Eightfold Path—one can work at reducing the suffering of repetitive maladaptive living.

\section{RELEVANT CONCEPTS IN BUDDHISM}

\section{Terms: Buddhism, Dharma Teachings, and Suffering}

I prefer to use the term "dharma teachings" instead of Buddhism. Dharma has been used in the Buddhist traditions to mean "law," "order" or "phenomena." We can think of it simply as the teachings about how things are. There are many "Buddhisms" that feature different emphases, beliefs, and customs. Some "Buddhisms" feature devotional religious practices, deities, and afterlives. Our focus as therapists is not on any of these added religious elements, but only on the fundamental teachings about how suffering comes about and how we can lessen or end it - that is what I will mean by "dharma teachings." It is, essentially, an experience-based psychology and philosophy_quite compatible with our ways of working as therapists—as I will outline below.

Samlin developed his "Aversion/Attachment Model of Client Suffering" (A/AMCS) by integrating three major components from the Buddhist tradition: the practice of mindfulness and two of the related ideas, "turning toward" and "skillful means." I will place them within the context of Buddhist metapsychology known as the Abhidharma, and then discuss some helpful ways to work with these and other ideas from this tradition. 
The Buddhist view sees our behavior, our cognitions, and our sense of self as a collection of conditions that tend to recur and keep us stuck in "suffering." "Suffering" is the usual translation of the Pali term dukkha, which may be more helpfully translated as "persistent unsatisfactoriness." It is a way of describing much of our experience of life. For many, the term "suffering" connotes too much intensity when used to describe our day-to-day maladaptive patterns of thought, emotion, and behavior. I, and most writers, do continue to use the term "suffering" but it is worth keeping in mind the alternative translation.

\section{Abhidharma as a Psychology Compatible With Western Psychotherapy}

\section{$\underline{\text { About the Abhidharma }}$}

The Abhidharma (literally, "higher teachings") is a metapsychology, a phenomenology, and an epistemology that dates back to the third century BCE, about 100-200 years after the Buddha. It is the essential "Buddhist Psychology" that comes closest to western psychology in identifying the nature and determinants of subjective experience and behavior. Although not the Buddha's words, it summarizes and expands his teachings that (a) sentient experience is a long sequence of conscious moments, and (b) the senses meeting the world produce a "self" structure within us that is conditioned, impermanent, subject to change, and lacking enduring substance. The problem is that we don't understand this, and we operate as though there is an actual enduring self.

That suffering is the central human experience is presented as the first Noble Truth. This truth is understood to be caused by "Three Marks." In order to understand how these teachings are relevant to the practice of psychotherapy, the Buddhist.org web site summarizes these marks.

The first mark is anicca, or Impermanence. All things in reality change and that change is constant. There is no permanent state because all things are dependent on other constantly changing things. This is also known as conditioned existence because all things are conditioned by what they are dependent upon. Even our mental states are constantly changing from one moment to the next. It is important to accept this concept so we can adjust to the reality of life and ease the anxiousness we feel in response to changing circumstances.

The second mark is anatta, or Insubstantiality. A person is not a distinct identity that is fixed. Each person exists as a process of changing aspects of being that are called skandhas. When these skandhas are put together they give the sense of an individual. However, this individual is insubstantial because the skandhas are impermanent, interdependent, and constantly changing. The five skandhas are rupa, the physical material of the universe; vendana, sensations that come from interaction with the rupa; sanna, the perception of matter and thought through sensations; sankhara, deliberate mental formation of a response to that perception; and vinnana, the state of mind resulting from a pattern of mental formations, or consciousness. Each skandha is dependent on the other, and none can exist if even one is removed. This changing process we identify as a person who can continue in rebirth, as a plant which continues the process of the plant from which it originates. 
The third mark of existence is dukkha, or Suffering. This mark can be understood in three ways. Suffering itself is understood in our direct experience of pain or uneasiness, but this is not our entire experience of life in general. We also experience dukkha in frustration when pleasant experiences end, and we long for more. The third means of understanding dukkha is the experience of not being completely satisfied when expectations are unfulfilled. This results in dissatisfaction (https://buddhists.org/buddhist-symbols/three-marks-ofexistence/).

\section{Dependent Arising}

It can be seen that the first two marks involve concepts familiar to psychologists, such as the conditioned nature both of our experience (through perceptions, sensation, consciousness, and cognition) and of our behavior. The part of the Abhidharma that focuses upon how these concepts interact to create and maintain our experience is known as the Doctrine of Dependent Origination, or by variations such as Dependent Origination, Dependent Arising, Dependent CoArising, or Conditioned Arising.

In essence, the doctrine of Dependent Arising explains that all of our human experience is a cyclic "maladaptive" pattern, conditioning upon conditioning, and that by understanding this one can be less and less driven by the conditions and conditioning process. One can enter the "stream of understanding" at any point. Noted contemporary Buddhist scholar, Thanissaro Bhikkhu, says:

A person aiming to put an end to suffering does not need to know all the ins and outs of dependent co-arising, because the practice can be completed by focusing on any one of its component factors. Once that one factor is understood, that understanding will spread to the other factors as well. Still, an appreciation of the complexity of dependent co-arising helps to explain why this is so (2008).

The Dalai Lama explains:

In Sanskrit the word for dependent arising is "pratityasamutpada.” The word pratitya has three different meanings - meeting, relying, and depending - but all three, in terms of their basic import, mean dependence. Samutpada means arising. Hence, the meaning of pratityasamutpada is that which arises in dependence upon conditions, in reliance upon conditions, through the force of conditions (1992).

For a more thorough presentation and explication of Abhidharma, specifically the Doctrine of Dependent Arising, and how the Buddhist tradition understands the conditioned shaping of consciousness, cognition, and behavior, see Guenther (1974).

\section{INTEGRATION ISSUES}

\section{Assimilative Integration}

Samlin's study is an assimilative integration (Messer, 1992) of Buddhist concepts into Time-Limited Dynamic Therapy (TLDP), with a considerable amount of theoretical fit. In order to examine if integrating dharma teachings could augment clients' healing, Samlin chose a model of therapy that was compatible with integration and that allowed for a brief treatment. I would 
agree that of the short-term dynamic therapies, TLDP is a particularly good fit with mindfulness concepts, since TLDP has, at its theoretical and therapeutic core, the identification and treatment of cyclic maladaptive patterns (CMPs). This model (and others such as Wachtel, Kruk, \& McKinney's [2005] longer-term approach) is conceptually quite compatible with the cyclic conditioning described in the Abhidharma's doctrine of Dependent Arising.

From the Buddhist perspective as described above, I propose that when assimilating ideas and practices from dharma teachings into the TLDP model with CMP at its theoretical core, we have strong compatibility, and the essential concepts and practices of the therapy and the dharma practices are little or not at all changed by the mix. Does it bend the TLDP model too far to ask it to accept the view that patients can see more of their thoughts and behaviors as repetitive maladaptive patterns that lead to suffering - more than just that which is focused upon in therapy? No. Does it change the therapist in some way incompatible with how she/he must work in the TLDP model? No (most likely it helps!). Does it do a disservice to the dharma when integrated into psychotherapy where more awareness is brought to emotion and quality of relationships than in traditional Buddhist training? No. Does the use of mindfulness impede or invalidate something essential about the experience of therapy? No (again, it probably helps]). I believe that an important reason why these answers are all no is because we are taking the dharma teachings about the end of suffering as a body of psychological ideas and recommendations and using them in a therapeutic enterprise that is quite consistent with the original intent described by the Buddha-to help people suffer less. Furthermore, it can be seen that many of the common factors of healing in therapy are important factors in the dharma teachings: compassion, presence, equanimity, acceptance, understanding, practice of new ways of seeing, and thinking and behaving. Neither psychotherapy nor dharma teachings distort nor bend the other's theoretical underpinnings beyond its original form and intent. In fact, I would argue that they synergize.

Beyond the more psychodynamically based TLDP, I think it could be contended that most of evidence-based, cognitive-behavioral therapy models allow for the dharma principles and practices to be integrated on a theoretical level as well. This is because the dharma's fundamental understanding of our suffering is conditioning. The word is actually used in the ancient Pali writings, and it means mainly what Pavlov and Skinner meant it as. The conditioned mind, senses, and body drive us. Our physiology and nervous systems are the wiring of conditioning, and they have evolved over time as both a great help to our adapting to our environment, but also a curse. We are too often needlessly gripped by our tendency to scan for danger, to remember frustrations and punishments, and to generate "adaptive" arousal when it is not needed. But the skillful management of this evolutionarily double-edged apparatus is more than ever within our reach, now supported by scientific research and clinical evidence as well as through millennia of peoples' lived experience. Dharma teachings and yogic self-regulation practices are a powerful body of ideas, techniques and skills to integrate into either form of therapy. The addition of self-regulation practices-methods to relax or activate the body and to regulate the breath and autonomic nervous system — should also be integrated, aided by simple, inexpensive devices for laptops or phones that train heart rate variability. 
Why Integrate Dharma Teachings?

\section{Theoretical Reasons}

These ideas and practices fit very well into contemporary cognitive-behavioral and psychodynamic approaches. The Abhidharmic core developed in Buddhist thought melds very well with Social Learning Theory's emphasis on how behavior and cognition are conditioned and maintained by complex interactions with others in the environment. Dharma teachings also integrate well with those psychodynamic approaches that emphasize the CMP's and interpersonal experience that is internalized into enduring mental and behavioral structures. In other words, conditioning again. The development and maintenance of maladaptive thinking and behavior that causes suffering is clearly the same target zone for these therapies as well as for the Buddha's teachings about suffering and the end of suffering.

\section{$\underline{\text { Scientific Reasons }}$}

It works. The research literature shows that mindfulness and related concepts add power to therapies, regardless of theoretical tradition. The work of Linehan (1993), Hayes, Strosahl, and Wilson (2011), and Segal, Williams and Teasdale ( 2012 )—together with the body of work from Jon Kabat-Zinn and colleagues (Kabat-Zinn, 2003)-amply demonstrate the utility of the dharma teachings and practices. Samlin's bibliography and also my own contribution on assimilative integration of eastern traditions (Morgan, 2001) contain many of the references supporting the integration of yogic and dharma teachings and practices. I predict much more will happen in this arena in the next 20 years-stay tuned...

\section{$\underline{\text { Practical Reasons }}$}

Dharma teachings are user-friendly. Clients accept them easily, develop new skills and perspectives, and find them helpful as part of their therapy and life in general. Dharma teachings normalize what has been seen as pathological and universalize the path toward less suffering and more skillful living. Therapists can self-disclose about their own ways of working with these challenges we all face.

The dharma teachings and practices fit well into problem-focused, short-term models of psychotherapy, supported by managed care insurance.

Learning about the dharma gives clients opportunities to go beyond the therapy hour to find good teachers; to read self-help books, websites and blogs; to attend supportive yoga and meditation groups and trainings; and to plug into a supportive community of people who learn and practice these skills.

\section{$\underline{\text { Personal Reasons }}$}

I've been impressed with the young therapists I've worked with and supervised who came to graduate school already quite experienced with the dharma teachings. Having a meditation practice, attending retreats and trainings, and studying dharma principles deepens therapists' skills and humanity and makes them better therapists earlier in their careers. I would argue that any therapist will be a better helper and model if she/he has studied, understood and practiced the 
dharma teachings. It is probably not going too far to also say that immersion in the dharma teachings can contribute to making one a better person - the perspective and skills that develop are broadly good for life and self-care.

Furthermore, in order to really use the dharma teachings as a therapist, I think they actually need to be practiced by the therapist. Segal, Williams and Teasdale (2012) found this out, as they reported in their study of mindfulness-based cognitive therapy for recurring major depression. When they realized that Kabat-Zinn and his colleagues actually all had meditation practices and used the dharma principles in their lives, it became clear that something powerful was being drawn from this well and passed along to the clients, and they began their own more personal explorations and practices.

\section{$\underline{\text { Pedagogical Reasons }}$}

It should also be emphasized how valuable it can be to include the dharma teachings in the training of psychotherapists. When students learn about and practice the dharma teachings, it helps them deal with the many difficulties of being a beginning therapist. Working towards selfacceptance, being nonjudgmental, cultivating an inquisitive and discriminative mind, developing better compassion and empathy, and deepening the quality of presence when sitting with peoples' suffering and accepting what is occurring in the moment - these all help beginning therapists accept tragic aspects of their own and their clients' lives with greater equanimity, and help them to better alleviate some of their clients' suffering while also caring for themselves.

\section{Thoughts on More Ways to Use the Dharma Teachings and Yogic Techniques in Psychotherapy}

I have not found it to be crucial that clients develop a regular meditation practice. Samlin's case reports show that typically not all clients are disciplined enough or ready to institute a regular formal meditation practice. The therapist should plant the seeds for it in therapy and teaching, but shouldn't expect clients to immediately adopt a regular mediation practice. Of course when clients practice meditation, it helps them bring the teachings to life and is the "gym" where skills of mind can develop. But most of the work occurs "off the cushion" where there are opportunities for the practice of becoming aware, loosening attachments, and reworking the highly conditioned patterns with everyday challenges. Therapy becomes a supportive collaboration in recognizing more of these patterns, practicing acceptance and tolerance, and regulating the conditioned affect, while developing more skillful means. And the greater amount of practice often comes later, after clients have seen the value of these teachings.

\section{Turning Toward}

Samlin made good use of this teaching, which is sometimes also presented as the choice to "move towards the flame." When we help clients learn to tolerate their painful emotions, memories, and judgments, they usually find that they don't suffer nearly as much as they feared. Obviously, severe trauma cases need extensive support and skills in autonomic/affect regulation in order to do this, but most clients who allow this exposure usually experience the lessening of fear and arousal. Tara Brach teaches her clients that "What you resist, persists," and uses the acronym RAIN as a reminder to recognize, accept, investigate, and not identify with the 
maladaptive emotions and behaviors (Brach, 2003). The dharma teachings about nonidentification are helpful here. If I do not "own" or identify with the negative memories and emotions, and if I have understood that my "self" is a collection of conditions and not who I am, then I have less "self" at stake and it is easier to allow and accept my failings, tragedies, and flaws without further suffering. Samlin's use of the "second arrow" teaching addresses this.

\section{Cultivating Present-Centered Attention}

The dharma teachings make clear that most of our suffering occurs when we are remembering the past or imagining the future. Cultivating present-centered awareness involves the same process that formal meditation practice addresses: noticing the mind's wanderings into past and future, accepting this because it has happened, and gently moving attention to the present, usually by becoming aware of the senses and the body. It is a source of constant amazement to me how reflexively the mind returns to its preoccupation with past and future, and how most of what we think can be characterized as "garbage mind." Helping clients to be more present is always beneficial. Practicing with formal meditation is important, but the everyday, every minute experience of noticing where the mind is and returning to the present is a constant opportunity for practice. The dharma teachers say, "When walking, just walk... when eating, just eat." On the topic of cultivating greater awareness of the present moment, I have found all of Eckhart Tolle's work, but especially the first volume, The Power of Now (Tolle, 1999), to be enormously helpful for clients to read or, even better, to listen to. He is able to present many complex ideas from the dharma, yogic, and other traditions in simple and accessible ways for clients to use as they cultivate present-centered awareness.

\section{Being Part of a "Sangha"}

The community of practitioners of the dharma teachings has been known as a "sangha" and it is generally true that one's path toward any goal is made easier if there is support and encouragement. When clients can feel themselves to be a part of a "sangha," whether in person or through Internet learning, social media or books, there is an enormous benefit. I have given clients information about talks and presentations, Internet links for blogs and courses, handouts, books, seminars, and retreat centers - all of which are helpful in supplementing the therapy and supporting clients in their growth. These then often stimulate clients to address important issues in the therapy as well.

\section{$\underline{\text { Regulation of the Nervous System }}$}

Finally, I'd like to recommend that therapists who integrate the dharma teachings into psychotherapy also learn about and use some of the very accessible equipment that helps clients to regulate their autonomic nervous systems using breathing and heart-rate variability training. Small low cost sensors and software/apps that connect to phones, laptops, or tablets are available that greatly assist people in learning how to use their breath and attention to change the state of their nervous systems for the better (e.g., see Heartmath Institute, https://www.heartmath.org/). I have purchased several of these and loan them to clients who can't afford to buy them. The ancient yogis developed elaborate systems of physical postures and breathing practices that have been scientifically investigated and shown to be effective in autonomic regulation. These devices 
assist greatly in this learning, and we should give clients these skills. If the ancient yogis had them, they would have used them!

\section{SUMMARY}

I had the good fortune to be exposed to the philosophy and practices of Yoga and Buddhism starting in my teens, and when I was in graduate training, I was even more fortunate to find the psychiatrists, psychologists, physicians, and Swamis at the Himalayan Institute of Yoga Science and Philosophy (https://www.himalayaninstitute.org/ ). They were the most sophisticated integrationists of the Yogic and Buddhist traditions during the 1970's and 80's, with the research capability of a psychophysiology lab and state-of-the-art biofeedback equipment. They produced many publications and training seminars devoted to presenting ways to use meditation, breathing, hatha yoga, and the wisdom of these traditions in medicine, psychotherapy, nutrition, and personal growth. (For a bibliography of many of the seminal publications from this Institute, see Morgan [2001]). Over the years since, we have all seen the explosion of interest and investigation into the ideas and practices of the Buddhist and Yogic traditions, and it is most heartening to know that from this ancient wisdom, many people have been, and will be, helped enormously in attaining greater physical and emotional well-being. Jason Samlin's excellent case studies are another fine contribution to this lineage by connecting dharmic principles to Time-Limited Dynamic Psychotherapy, and by illustrating their use through embodying them in concrete clinical situations and therapy process.

\section{REFERENCES}

Brach, T. (2003). Radical acceptance: Embracing your life with the heart of a Buddha. NY: Bantam.

Buddhists.org. (2012) Buddhist symbols and practices. https://buddhists.org/buddhistsymbols/three-marks-of-existence/

Dalai Lama (1992), The meaning of life, translated and edited by Jeffrey Hopkins, Somerville, MA: Wisdom Publications.

Guenther, H.V. (1974). Philosophy and psychology in the Abhidharma. Boston: Shambala Publications.

Hayes, S., Strosahl, K, \& Wilson, K. (2011). Acceptance and Commitment Therapy, 2nd edition. NY: Guilford Press

Kabat-Zinn, J. (2003). Mindfulness-based interventions in context: Past, present, and future. Clinical Psychology: Science and Practice,10, 144-156.

Linehan, M. (1993). Cognitive-behavioral treatment of borderline personality disorder. New York, NY: Guilford Press.

Messer, S. B. (1992). A critical examination of belief structures in integrative and eclectic psychotherapy. In J. C. Norcross \& M. R. Goldfried (Eds.), Handbook of psychotherapy integration, pp. 130-165. New York: Basic Books.

Morgan, D. (2001) Assimilation from the East and the spectrum of consciousness. Journal of Psychotherapy Integration, 11, 87-104. 
Samlin, J. (2016). Integrating Time-Limited Dynamic Psychotherapy and a Buddhism-inspired Aversion/Attachment Model of Client Suffering: The cases of "Beth" and "Amy. Pragmatic Case Studies in Psychotherapy, 12(4), Article 1, 238-308. Available: pcsp.libraries.rutgers.edu.

Segal, Z., Williams, M., \& Teasdale, J. (2012). Mindfulness-based cognitive therapy for depression, 2nd edition. NY: Guilford Press.

Thanissaro Bhikkhu (Geoffrey DeGraff) (2008). The shape of suffering: A study of Dependent Co-arising. Barre, MA: Metta Forest Publications.

Tolle, E. (1999). The power of now. Novato, CA: New World Library.

Wachtel, P.L., Kruk, J.C., \& McKinney, M.K. (2005). Cyclical psychodynamics and integrative relational psychotherapy. In J. Norcross \& M. Goldfried (Eds.), Handbook of psychotherapy integration. $2^{\text {nd }}$ edition, pp. 172-195. NY: Oxford University Press. 